\title{
Understanding the Molecular Biology of SARS-CoV- 2 and the COVID-19 Pandemic: A Review
}

\author{
Sarah Alsobaie \\ Department of Clinical Laboratory \\ Science, King Saud University, Riyadh, \\ II45I, Saudi Arabia
}

\begin{abstract}
Coronaviruses are named after the crown-like spike proteins on their surface. In the 21 st century, three coronaviruses, namely severe acute respiratory syndrome coronavirus 2 (SARS-CoV-2), SARS-CoV, and Middle East respiratory syndrome related coronavirus (MERS-CoV), have emerged in the human population, presumably evolving from pathogens infecting other animals. Coronaviruses are enveloped viruses responsible for $15-30 \%$ of the atypical pneumonia cases in humans worldwide. The current coronavirus disease 2019 (COVID-19) pandemic is caused by the newest SARS virus, SARS-CoV-2, an enveloped, positive-sense, single-stranded RNA betacoronavirus of the family Coronaviridae. As of April 2021, the World Health Organization has reported more than 3 million deaths from COVID-19 and more than 140 million people have been infected with the virus, thereby making it the worst SARS pandemic of all time. Here, I review the current understanding of the molecular biology of coronaviruses and their host interactions, bringing together knowledge of the infection process to aid in the development of therapeutic drugs and/or vaccines against SARS-CoV-2. I also briefly overview the current situation of available treatments, vaccinations, and emerging strains.
\end{abstract}

Keywords: ACE2, coronavirus, spike protein, mechanism, vaccine pandemic

\section{Introduction}

Coronaviruses are characterized by and named for the crown-like spikes on the virion surface. There are four main subgroups of coronaviruses, alpha, beta, gamma, and delta. Alpha and beta subgroups are suggested to have originated from bats and mammals, whereas gamma and delta subgroups primarily infect birds. There are four common human coronaviruses, 229E (Alphacoronavirus), NL63 (Alphacoronavirus), OC43 (Betacoronavirus), and HKU1 (Betacoronavirus). NL63 and HKU1 were recently discovered after the severe acute respiratory syndrome (SARS) epidemic but are thought to have been circulating in the human population for some time. ${ }^{1}$ Coronaviruses are enveloped viruses responsible for $15-30 \%$ of atypical pneumonia in humans worldwide. ${ }^{2}$ In the $21 \mathrm{st}$ century, three coronaviruses, SARS coronavirus (SARS-CoV), Middle East respiratory syndrome related coronavirus (MERS-CoV), and SARS-CoV-2, have emerged in the human population, presumably after transmission from other animals. ${ }^{3}$ The intermediate host of SARS-CoV is the civet or raccoon and that of MERS-CoV is the camel, ${ }^{4}$ but the host of the current SARS-CoV-2 pandemic strain is yet to be proven, although it is believed to be closely related to BatCov RaTG13 (Table 1). Although the RaTG13 bat virus exhibits similarity to SARS-CoV-2 across the
Correspondence: Sarah Alsobaie Department of Clinical Laboratory Science, King Saud University, Prince Turki Alawal Street, Riyadh, I I45 I, Saudi Arabia

Tel +966507/910II

Fax +966114677580

Email salsobaie@ksu.edu.sa 
genome, coronaviruses in Malayan pangolins (Manis javanica) remain closest to SARS-CoV-2. ${ }^{5}$ In particular, all six key receptor-binding domain (RBD) residues are identical in the coronaviruses of $M$. javanica and SARS-CoV-2. ${ }^{6,7}$

The fact that there have been three events of widespread zoonotic transmission within the past 20 years is concerning, and it suggests that additional emergence events are likely to occur in the future. ${ }^{8}$ During the first SARS pandemic in 2002, more than 8000 cases and 774 deaths were reported worldwide. However, fewer numbers of MERS cases have been reported - 2567 cases to date; however, 866 total deaths have resulted (from the WHO website: https://www.emro.who.int/health-topics/mers-cov /mers-outbreaks.html, viewed February 2021). The current virus, SARS-CoV-2, is the most pathogenic of the three coronaviruses, resulting in more than 3.1 million deaths from coronavirus disease 2019 (COVID-19) and more than 150 million people infected worldwide as of April 2021. Whereas the majority of COVID-19 cases are asymptomatic, symptomatic patients can experience mild to severe symptoms. Mild symptoms include fever, cough, headache, and fatigue, with mild or no pneumonia, and with severe clinical manifestations, acute respiratory syndrome, hypoxia, and dyspnea can develop. In critical cases, patients suffer from multi-organ dysfunction, respiratory failure, and shock. Disease fatality rates are higher in older people with chronic comorbidities such as diabetes, coronary artery disease, hypertension, chronic obstructive disease, and obesity. Despite the relatively

Table I Zoonotic Transmission of Coronaviruses

\begin{tabular}{|l|l|l|l|l|}
\hline Virus & $\begin{array}{l}\text { Origin of } \\
\text { Pathogen }\end{array}$ & $\begin{array}{l}\text { Natural } \\
\text { Reservoir } \\
\text { Host }\end{array}$ & $\begin{array}{l}\text { Virulent } \\
\text { Coronavirus }\end{array}$ & $\begin{array}{l}\text { Cell } \\
\text { Receptor }\end{array}$ \\
\hline $\begin{array}{l}\text { SARS- } \\
\text { CoV }\end{array}$ & $\begin{array}{l}\text { Palm civets, } \\
\text { raccoon, } \\
\text { dogs, } \\
\text { domestic cat, } \\
\text { and ferret } \\
\text { badgers }\end{array}$ & Bat & SARS & ACE2 $^{69}$ \\
\hline $\begin{array}{l}\text { MERS- } \\
\text { CoV }\end{array}$ & $\begin{array}{l}\text { Dromedary } \\
\text { camels }\end{array}$ & Bat & MERS & DPP4 $^{70}$ \\
\hline $\begin{array}{l}\text { SARS- } \\
\text { CoV-2 }\end{array}$ & Unknown & Unknown & COVID-19 & ACE2 $^{7}$ \\
\hline
\end{tabular}

Abbreviations: SARS-CoV, severe acute respiratory syndrome coronavirus; MERS-CoV, Middle East respiratory syndrome related coronavirus; COVID-19, coronavirus disease 2019; ACE2, angiotensin-converting enzyme 2; DPP4, dipeptidyl peptidase 4. high number of deaths, the rate of recovery from COVID-19 is substantial; the death rate varies regionally between $0.8 \%$ and $14.5 \%$ of the total population (mortality analyses, Johns Hopkins University of Medicine https:// coronavirus.jhu.edu/data/mortality; for daily case report, please see the World Health Organization [WHO] coronavirus disease dashboard at https://covid19.who.int/). The actual number of presumed cases is thought to be much higher owing to the current testing limitations, ${ }^{9}$ and the number of cases is expected to continue to grow exponentially. ${ }^{10}$ The nomenclature of the new emerging coronavirus as SARS-CoV-2 has been found to be misleading owing to its differences from previous SARS-CoV in epidemiology, transmission, and unique genetic structure, although the two viruses share approximately $79 \%$ similarity in genome structure and cause severe acute respiratory syndrome. It was suggested that the virus be named nCov19 to resemble the disease announced by the WHO, COVID-19. ${ }^{11}$

\section{Virus Genomic Structure}

The current COVID-19 pandemic is caused by the novel coronavirus strain SARS-CoV-2, a positive-sense, singlestranded enveloped RNA belonging to the Coronaviridae family $^{12}$ (Figure 1A). The SARS-CoV-2 genome is $>30 \mathrm{~kb}$ in length and consists of 14 open reading frames (ORFs) encoding 27 proteins. $^{13}$ The $5^{\prime}$ end of the SARS-CoV-2 genome consists of ORF $1 \mathrm{a} / \mathrm{b}$ encoding a polyprotein that is post-translationally cleaved into 16 non-structural proteins (nsp1-16), which form the replicase/transcriptase complex (RTC). This complex contains enzymes involved in the replication mechanism, including papain-like protease (nsp3), main protease (nsp5), nsp7-nsp8 primase complex, primary RNA-dependent RNA polymerase (RdRp; nsp12), helicase/triphosphatase (nsp13), exoribonuclease (nsp14), endonuclease (nsp15), and N7- and 2'O-methyltransferases (nsp10/nsp16). The 3' terminus of the viral genome contains ORFs encoding the four main structural proteins, spike (S), envelope (E), membrane $(\mathrm{M})$, and nucleocapsid $(\mathrm{N})$, as well as nine putative accessory factors (Figure 1B). ${ }^{14,15}$

The virus uses host machinery to produce its lipid envelope, which is studded with several $\mathrm{S}$ proteins giving the virus a crown-like appearance. The $\mathrm{M}$ glycoprotein, also called the matrix protein, is the most abundant structural protein, traversing the viral envelope and attaching the viral membrane to the nucleic acid within the virion. The $\mathrm{N}$ protein is 
A

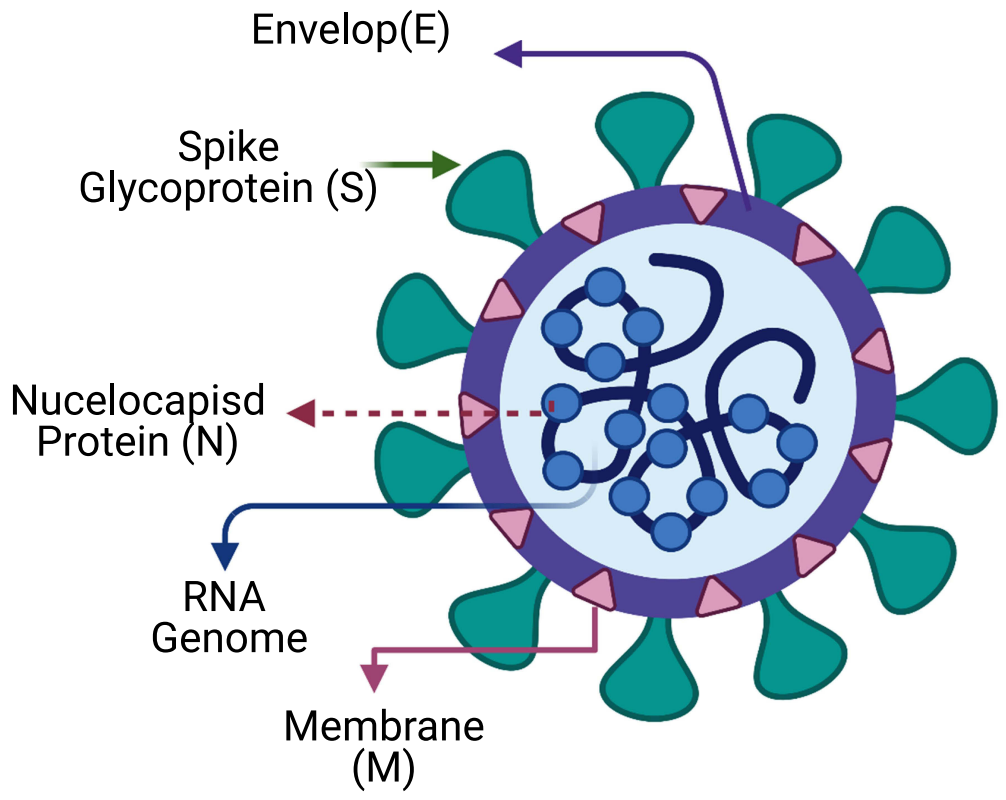

B

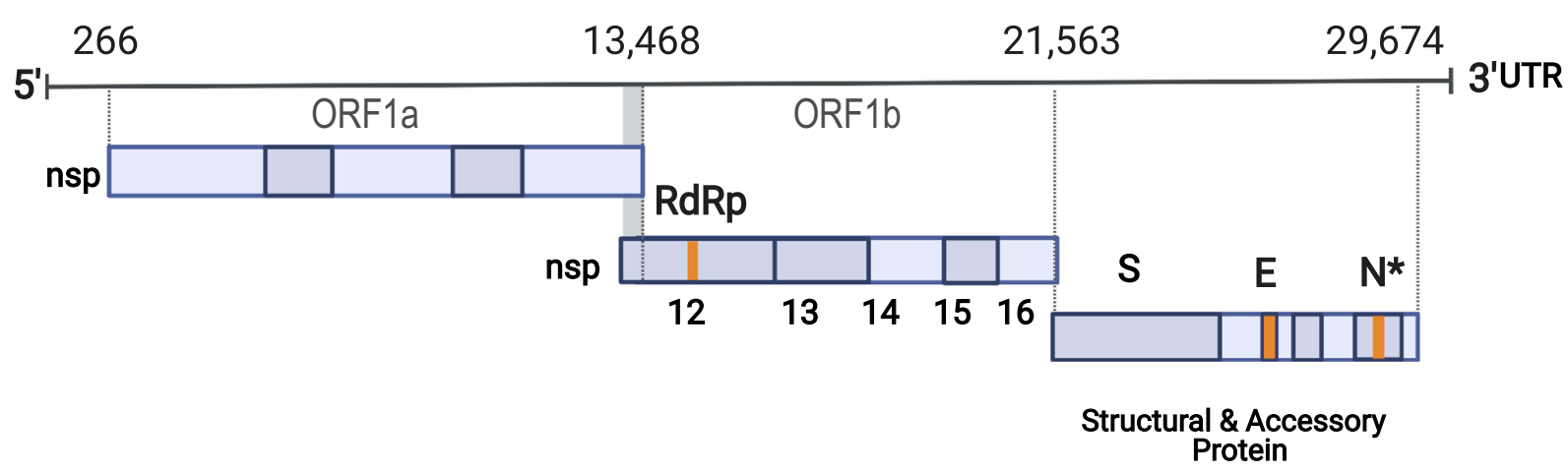

Figure I Schematic diagram of SARS-CoV-2: (A) SARS-CoV-2 is a positive-sense, single-stranded enveloped RNA.

Notes: The lipid envelope $(E)$ is studded with several spike $(S)$ glycoproteins giving the virus a crown-like appearance. The membrane (M) glycoprotein is the most abundant structural protein and spans the envelope. (B) The $5^{\prime}$ end of the SARS-CoV-2 genome consists of open reading frame (ORF) Ia/b that encodes a polyprotein, which is posttranslationally cleaved into 16 non-structural proteins (nspl-16), including RNA-dependent RNA polymerase (RdRp). The 3' terminus of the viral genome contains ORFs encoding the four main structural proteins, spike $(S)$, envelope $(E)$, membrane $(M)$, and nucleocapsid (N), as well as nine putative accessory factors. Figure created with BioRender.com. Figure adapted from Wang N, Shang J, Jiang S, Du L. Subunit vaccines against emerging pathogenic human coronaviruses. Front Microbiol. 2020; I :298. ${ }^{30}$ Creative Commons Attribution License (CC-BY 4.0; https://creativecommons.org/licenses/by/4.0/legalcode).

important for the morphogenesis phase of the viral life cycle (Figure 1A). ${ }^{14}$

The $\mathrm{S}$ protein plays a critical role in promoting cell attachment and fusion of the virus to the host membrane; it is trimeric and contains two distinct domains, the RBD at the amino-terminus of the S1 subunit and the carboxyterminus domain (CTD) of the S2 subunit, which is responsible for membrane fusion. ${ }^{16}$ SARS-CoV and SARS-CoV-2 share a highly conserved $\mathrm{S}$ protein RBD with $79.5 \%$ genome sequence identity. ${ }^{8}$ Cryo-electron microscopy images of SARS-CoV-2 showed sequence conservation of all related coronaviruses across the S2 subunit CTD. ${ }^{17,18}$ However, the S1 subunit RBD protein sequence contains unique regions, and this uniqueness tends to be common to coronaviruses in general. This is likely a result of intense evolutionary pressure due to constant interactions with the host immune system. ${ }^{19}$

SARS-CoV-2 antigenic evolution continues to be observed, particularly in the spike protein RBD. The first variant was reported and sampled in Italy in February of 2020, a D614G mutation in the S protein gene. Over time, this became the dominant variant displacing the original SARS-CoV-2 strain. ${ }^{20}$ Thereafter, additional variants have been emerging in different countries. The most widespread variant to date is B.1.1.7 or SARS-CoV-2 VOC 202012/ 01 , a variant that emerged in the United Kingdom and was 
Table 2 Variants of SARS-CoV-2 Reported Worldwide ${ }^{20}$

\begin{tabular}{|l|l|l|l|l|l|l|l|}
\hline Variant & $\begin{array}{l}\text { Country } \\
\text { of First } \\
\text { Case }\end{array}$ & $\begin{array}{l}\text { Countries } \\
\text { Reported in } \\
\text { (no.) })^{\mathbf{n}}\end{array}$ & $\begin{array}{l}\text { Transmissibility } \\
\mathbf{b}\end{array}$ & Virulence & $\begin{array}{l}\text { Number } \\
\text { of } \\
\text { Mutation }\end{array}$ & $\begin{array}{l}\text { Diagnostic } \\
\text { Assay }\end{array}$ & Mutation Type \\
\hline B.I.I.7 & $\begin{array}{l}\text { United } \\
\text { Kingdom }\end{array}$ & 137 & $43 \%$ to $90 \%{ }^{71}$ & NA & 18 & Work & $\begin{array}{l}\text { H69/V70 del,YI44 del, N50IY, } \\
\text { A570D, P68IH, SI06/GI07/FI08 } \\
\text { del }\end{array}$ \\
\hline B.I.35I & $\begin{array}{l}\text { South } \\
\text { Africa }\end{array}$ & 85 & NA & NA & 8 & Work & $\begin{array}{l}\text { L242/A243/L244 del, K4I7N, } \\
\text { E484K, N50IY, SI06/GI07/FI08 } \\
\text { del }\end{array}$ \\
\hline P.I & Brazil & 52 & $42 \%{ }^{72}$ & NR & 21 & Work & $\begin{array}{l}\text { K4I7T, E484K, N50IY, SI06/ } \\
\text { GI07/FI08 del }\end{array}$ \\
\hline
\end{tabular}

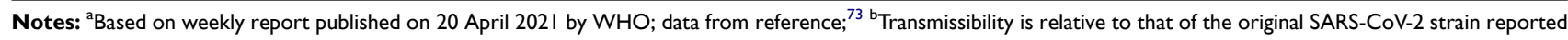
in UK, USA, Ireland, Switzerland, and Denmark; 'Diagnostic test capable of identifying those variants.

Abbreviations: NA, not available; NR, not reported.

reported to the WHO in December 2020 (Table 2). Initial clinical studies showed that the 17-nucleotide mutation or deletion $^{21}$ increases the transmissibility of the virus with little or no impact on severity, diagnosis, pathogenesis, reoccurrence, or response to vaccination. ${ }^{22}$ According to the WHO report on April 20, 2021, this variant has been reported in over 137 different countries. Another variant reported on December 18, 2020 emerged in South Africa, was named B.1.351 or 501Y.V2 after the mutation showed high similarity to the variant of the UK lineage (https:// www.who.int/publications/m/item/weekly-epidemiological -update-on-covid-19-20-april-2021). The latest variant, P.1, was identified first in January 2021 in Japan from travelers returning from Brazil. ${ }^{23}$ Various aspects of these three variants are summarized in Table 2.

\section{Mechanism of Viral Cell Entry}

Both SARS-CoV-2 and SARS-CoV bind to the angiotensin-converting enzyme 2 (ACE2) receptor protein to gain entry into the host cell, whereas MERS-CoV uses dipeptidyl peptidase 4 (DPP4) as a host receptor through the RBD (CTD) region. ${ }^{17}$ ACE2 is located on the membrane surface of host cells and after virus binding, proteolytic activity is critical for fusion of the S protein; its exposure facilitates fusion of the virus with the host membrane. Thereafter, host cell proteolytic cleavage of the S protein into S1 and S2 subunits proceeds via activity of the transmembrane protease serine 2 (TMPRSS2) and human airway trypsinlike protease (HAT) ${ }^{24}$ The S2 subunit is composed of a fusion peptide (FP) and heptad repeat domains (HR)1 and HR2. Upon insertion of the hydrophobic FP into the host membrane, the pre-hairpin coiled coils of HR1 and HR2 undergo irreversible conformational changes and interact to form a six-helix bundle. This brings the viral envelope and cell membrane close enough for host penetration. ${ }^{25}$

\section{SARS-CoV-2 Distinguishing Criteria}

Three factors have been identified as possible contributors to the virulence of SARS-CoV-2, and they might impact pathogenicity. They include the following: 1) differences in the $\mathrm{S}$ protein $\mathrm{RBD}, 2$ ) differences in properties of accessory proteins, and 3) the addition of a polybasic cleavage site in the $\mathrm{S}$ protein. Interestingly, five of the six critical amino acids in the $S$ protein $R B D$ that are necessary for interaction of $\mathrm{S}$ with the ACE2 receptor are different between SARS-CoV and SARS-CoV-2. ${ }^{17}$ The SARS-CoV-2 S protein exhibits a stronger binding affinity to ACE2 than that of the SARS-CoV S protein, which could lead to the reportedly higher transmissibility and contagiousness of SARS-CoV-2 during the current pandemic. ${ }^{19,26}$ As indicated earlier, the genome sequences of SARS-CoV-2 and SARS-CoV share more similarities than differences. The differences are associated with the accessory proteins ORF33a, ORF8b, ORF6, and protein $\mathrm{E}^{27}$ which are known to be involved in the NLRP3 inflammasome complex and innate immunity, perhaps countering the interferon response. ${ }^{28}$ The functions of many of the accessory proteins are not yet established. It would be worthwhile to identify whether the differences in these proteins contribute to the enhanced virulence and pathogenicity of SARS-CoV-2., ${ }^{8,17}$ 
The acquisition of a polybasic cleavage site (RRAR) at the junction of S1 and S2 allows for effective cleavage by furin and other proteases and is a determinant of viral infectivity and host range. ${ }^{7}$ In addition to this polybasic cleavage site, there are $O$-linked glycans and RBD mutations that appear to be specific to SARS-CoV-2; they were not previously seen in other B-lineage betacoronaviruses. Insertion of a polybasic site increases the transmissibility of pathogenic influenza viruses. ${ }^{7,29}$ Thus, it is important to elucidate whether the same is true for SARS-CoV-2. ${ }^{30}$

\section{Virion Replication and Assembly}

Coronavirus RNA transcription occurs in the host cytoplasm via the catalytic subunit RdRp. Viral transcription generates a large viral mRNA transcript containing two overlapped ORFs, 1a and 1ab, and the other subgenomic mRNAs (sgmRNAs). In general, all of the mRNAs encode polyproteins with few exceptions; however, only the most $5^{\prime}$-ORF of the smallest mRNA is translatable. ${ }^{31}$

All of the mRNAs possess a 5'-common leader sequence derived from the 5 '-end of the viral genome. This short stretch of sequence represents a signal for the discontinuous transcription of sgmRNAs. The transcriptional regulatory sequences (TRSs) act as a "slow-down" or "stop" signal for the RTC. ${ }^{15}$ mRNA gene expression is copied to a direct base pair with the leader TRS strand and the $3^{\prime}$ end of the viral genome. ${ }^{32,33}$ This discontinuous transcription mechanism is quite complex and orchestrated by a replicase that includes a polymerase and several other proteins required for functional integration of the RNA polymerase, capping, and proofreading activities. The mechanism of discontinuous transcription likely facilitates the extraordinary recombination rates observed within coronaviruses, which are as high as $\sim 25 \%{ }^{34}$ Most RNA viruses, and especially positive-sense RNA viruses, have vanishingly low levels of recombination. This unique feature of the large and complex genomic RNA of coronaviruses might have evolved to enable the maintenance of such large genomes. ${ }^{35}$

The SARS-CoV-2 replication complex is composed of nsp12, 10, and $14 .{ }^{36,37}$ The nsp12 RdRp is the major machinery of transcription/translation; the holoenzyme structure is constructed by two processivity factors forming nsp7/nsp8 complexes. $^{37}$ The polymerase complex (nsp12/8/7) is associated with nsp14, which serves in both capping and as a source of exonuclease activity. The heterodimer structure of nsp14 is composed of a bifunctional enzyme of two different domains, a basic exoribonuclease (ExoN) activity domain involved in proofreading and a methyl transferase domain involved in the mRNA capping reaction. These two domains are separated by a flexible hinge region, which allows the protein to be positioned in different orientations for the mismatch repair mechanisms to occur. ${ }^{38}$ Silencing nsp14ExoN induces a 21 -fold increase in genome mutations in infected cells compared to that observed in wild-type viruses. ${ }^{39,40}$ Acquisition of such complex RdRp activity has allowed coronaviruses to evolve with a larger genome and to increase their fidelity rate. ${ }^{41}$ In addition, there are a variety of other viral processing proteins, undefined sets of cellular proteins, and activities involved in orchestrating this discontinuous transcription mechanism, which are not all biochemically understood. ${ }^{42}$

Viral-infected cells exhibit convoluted membranes and interconnected double-membrane vesicles where viral replication and transcription occur. These are derived from the endoplasmic reticulum (ER). The compartmentalization of different RNA parts of replication in different vesicles protects the viral genome from potential attack by antiviral mechanisms, exonucleases, or nucleases generally present in the host cytosol. ${ }^{43}$ It can also help concentrate the factors necessary to efficiently replicate and transcribe the viral genome. Integral membrane proteins that are part of the replication complex are thought to function in vesicle biogenesis, and the three replication components, nsp3, 4, and 6 , are predicted to have transmembrane domains and to be indirectly involved in vesicle formation. ${ }^{44,45}$ Expressing nsp3 and nsp4 alone, outside of the context of infection, is sufficient to drive doublemembrane vesicle formation. ${ }^{45}$ This occurs through an interaction between the luminal loops of nsp 3 and nsp4 proteins that drive membrane curvature and vesicle formation. ${ }^{46}$ Components of the proteome are associated with these RTCs.

The co-expression of $\mathrm{M}$ protein with either $\mathrm{E}$ or $\mathrm{N}$ protein is sufficient to form membrane-enveloped vesicles and virus-like particles. ${ }^{14}$ Assembly is driven first by the association of N protein with the genomic RNA leading to the formation of helical nucleic acids. Mature coronavirus particles inserted into the ER and then bud into the ER-Golgi intermediate compartment. Assembly involves the interaction among components of the viral $\mathrm{S}, \mathrm{M}$, and $\mathrm{E}$ proteins and the interlinkage of proteins to the viral genome. After the accumulation of virions in large, smooth-walled vesicles, they are released from the host cells by exocytosis. 


\section{Immune Response}

SARS pathogenesis has been shown to be related to delayed interferon (IFN)-1 signaling and subsequent immune toxicity. ${ }^{47,48}$ Immunopathology associated with these infection responses are thought to cause acute respiratory distress syndrome. Several nsps, accessory factors, and matrix nuclear proteins were identified as putative interferon antagonists. Early prevention of the antiviral interferon response results in high initial viral titers and the accumulation of less toxic inflammatory monocyte-macrophages (IMMs). This results in elevated lung cytokine/chemokine levels, vascular leakage, and impaired virus-specific $\mathrm{T}$ cell responses. Knockdown of the IFN- $\alpha \beta$ receptor or IMM depletion prevents the development of SARS-CoV-associated pneumonia, which can be lethal. ${ }^{48}$ A key coronavirus pathogenicity factor, nsp1, restricts gene expression originating from the host cell via a multi-pronged approach. Nsp1 interacts directly with the 40S ribosomal subunit to block the translation of host RNAs. Nsp1 also mediates endonucleolytic cleavage of host RNAs leading to broad, accelerated degradation. Widespread RNA degradation is also an immune evasion tactic to delay the IFN response. Mice infected with a wild-type virus die approximately 6 days after infection, but when the nsp1 protein is mutated, survival improves. ${ }^{48}$

Beyond the nsp1 virulence factor, several other proteins contribute to virus infectivity, such as nsp7 and nsp8 ${ }^{49,50}$ These two proteins play a role in IFN degradation for both SARS-CoV and MERS-CoV. Additionally, most of the structural proteins, including the $\mathrm{N}$ protein, which were found to regulate the host-cell cycle by preventing the $\mathrm{S}$ phase, block or antagonize the immune response by preventing the virus from presenting on cells. ${ }^{51,52}$ Understanding the infective properties of these proteins is essential for the development of novel therapeutic targets.

The neutralizing antibodies produced by natural immunity mainly target the RBD at the amino-terminus of the S1 subunit. Convalescent plasma from recovered donors has been used as treatment or prophylaxis to prevent the disease ${ }^{53}$ However, a clinical trial in Canada has stopped recruiting patients due to a lack of significance. Antibodies' durability after infection varied between 3 to 7 months. Diminishing IgG and IgA antibodies after a natural infection is normal but further studies are required to assess the ability of both humoral and cellular immunity to remember the infection. Results from longitudinal cohort studies of neutralizing antibodies vary between approximately $77-89 \%$ protection, with an incidence of reinfection less than $1 \%$ in the 5-7 months following the initial infection. ${ }^{54-56}$ In these studies, it was found that high neutralization titers correlate with the severity of disease and older age of patients. ${ }^{54}$ They also correlate with a high increment of inflammatory factors found in severely ill patients.

There are few studies addressing the immunogenicity, durability, and efficacy of natural or vaccine-acquired natural immunity toward new emerging variants. A serological cross-reactivity study with D614G mutants ${ }^{57}$ showed that the presence of antibodies provides cross-protection with parental strains but there was marginal drop when cross-recognizing B.1.1.7 and a further drop with B.1.351. ${ }^{22}$ The best way to understand the immune response further is through virus challenge studies, which cannot be performed due to the lack of proper treatment and the possible severity of the consequences. The UK government has recently approved the first human challenge study to take place among a healthy young population. The controlled human infection trial will help to understand more about host responses to the organism and further shed light on the pathogenesis of Covid-19.

\section{Pathophysiology of Disease and Clinical Management}

Positive feedback initiated by delayed IFN $\gamma$ production, cytokine secretion, IL-6 overproduction, and neutrophil and macrophage activation will cause a cytokine storm, acute respiratory distress, sepsis, and multiple organ dysfunction in critical cases. ${ }^{58}$ The disease pathophysiology can also involve the development of severe macro- and micro-vascular disorders, which result in a systemic hypercoagulable state and severe vascular injury, leading to thrombosis. ${ }^{27,59}$ This can either be due to immune dysregulation and a cytokine storm or the high expression of ACE2 in endothelial tissue (the site of entry for SARSCoV-2). ${ }^{60}$ The combination of these disease manifestations will lead to a ventilation/perfusion mismatch and severe dyspnea.

The underlying pathophysiology of the disease described previously herein requires a combination of different drugs, including anti-inflammatory, anticoagulants, antiviral, antibacterial, and supplemental oxygen. ${ }^{61}$ Such drugs might not directly fight the virus but instead are used to prevent or reduce its complications. Drugs such 
as chloroquine and hydroxychloroquine, previously approved as antimalarial drugs, have shown promising results in preventing viral multiplication; however, clinical trials did not confirm their efficacy. ${ }^{62,63}$ Currently, the first FDA-approved drug, remdesivir, has not shown any decrease in the death rate, but improvements in morbidity related to kidney or liver failure have been reported. ${ }^{64}$ All other drugs under investigation for SARS-CoV-2 treatment fall into two different categories, antiviral drugs to stop viral growth and immune system boosters, such as convalescent plasma from survivors, used to modulate recipient immunity. Different clinical trials using convalescent plasma conducted in the UK and Canada (Concor-1 clinical trial https://clinicaltrials.gov/ct2/show/NCT04348656 and REMAP-CAP https:/www.remapcap.org/) did not show promising results for critical inpatients; however, patient lung damage might have hindered the efficacy. Both trials stopped recruiting patients, although patients who were not intubated did show improvements in mortality rates. ${ }^{65}$ Thus, this type of treatment can be helpful during the course of disease, especially if upcoming variants continue to evolve and erode the currently available vaccine and drug therapies.

Based on the latest update on the WHO website (https://www.who.int/publications/m/item/draft-landscapeof-covid-19-candidate-vaccines), there are more than 80 candidate vaccines undergoing clinical trials and 180 preclinical vaccines in development. Those approved largely rely on genetic information of the $\mathrm{S}$ protein as the target antigen, such as mRNA (Pfizer and BioNTech and Moderna), adenovirus vector (Oxford University and AstraZeneca), peptide (EpiVacCorona), or protein subunit (Novavax) vaccines. Other vaccines are being produced using classical methods either via the inactivation or attenuation of the wild-type virus, such as BBIBP-CorV developed by the Beijing Institute of Biological Products and CoronaVac by Sinovac. ${ }^{66}$

\section{Future Directions}

There are several basic questions regarding the molecular biology of SARS-CoV-2 that need to be answered. First, the role of the insertion of a polybasic site in increasing the binding affinity of the SARS-CoV-2 S protein to the human ACE2 receptor and how this facilitates disease transmission and spread are unknown. ${ }^{67}$ Second, the functional significance of the accessory proteins and their impact on both in vivo growth and virulence of the virus are unclear. ${ }^{68}$ The roles of other non-structural and host proteins in orchestrating the sophisticated replication/transcription complex and coordinating the viral life cycle in time and space are also not fully understood. Finally, it is not known what enables SARS-CoV-2 to maintain a sufficient mutation rate during trans-species movement and host-adaptation, despite its relatively large RNA genome.

\section{Conclusions}

During the past 60 years, many zoonotic coronaviruses have emerged, crossing barriers between mammalian species and causing concern for the future. The current coronavirus pandemic is considered the most contagious of this century, infecting 150 million people worldwide and causing nearly 3 million deaths so far. To date, different SARS-CoV-2 variants have evolved, and the implications of these mutations on the detection, transmission, vaccination, and severity of disease are yet to be determined. Acquiring the highest herd immunity threshold among the population via natural or vaccinal immunity is critical to prevent and reduce the infectious disease, as well to halt viral evolution. This review covered the current state of the literature regarding the molecular mechanisms by which the virus infects, replicates, and evolves, as well as the pathogenesis and immune response of the host. It is important, more than ever before, to understand more about viral RNA synthesis, immune evasion, and pathogenesis as we encounter ever more emerging viruses in host populations.

\section{Data Sharing Statement}

Data sharing is not applicable to this article as no datasets were generated or analyzed during the current study.

\section{Acknowledgments}

This research did not receive any specific grant from funding agencies in the public, commercial, or non-profit sectors.

\section{Author Contributions}

Sarah F. Alsobaie is the sole author of this article. The author made substantial contribution to conception and design, acquisition of data, or analysis and interpretation of data; took part in drafting the article or revising it critically for important intellectual content; agreed to submit to the current journal; gave final approval of the version to be published; and agree to be accountable for all aspects of the work. 


\section{Funding}

There is no funding to report.

\section{Disclosure}

The author declared that they have no known competing financial interests or personal relationships that could have appeared to influence the work reported in this paper and reported no conflicts of interest for this work.

\section{References}

1. Pal M, Berhanu G, Desalegn C, Kandi V. Severe acute respiratory syndrome coronavirus-2 (SARS-CoV-2): an update. Cureus. 2020. doi:10.7759/cureus.7423

2. Cunha BA. The atypical pneumonias: clinical diagnosis and importance. Clin Microbiol Infect. 2006;12:12-24. doi:10.1111/ j.1469-0691.2006.01393.x

3. Letko M, Marzi A, Munster V. Functional assessment of cell entry and receptor usage for SARS-CoV-2 and other lineage B betacoronaviruses. Nat Microbiol. 2020;5(4):562-569. doi:10.1038/ s41564-020-0688-y

4. Perlman S, Mcintosh K. Coronaviruses, Including Severe Acute Respiratory Syndrome (SARS) and Middle East Respiratory Syndrome (MERS). 2020.

5. Lam TT-Y, Jia N, Zhang Y-W, et al. Identifying SARS-CoV-2-related coronaviruses in Malayan pangolins. Nature. 2020;583 (7815):282-285. doi:10.1038/s41586-020-2169-0

6. Sohrabi C, Alsafi Z, O’Neill N, et al. World Health Organization declares global emergency: a review of the 2019 novel coronavirus (COVID-19). Int $J$ Surg. 2020;76:71-76. doi:10.1016/j. ijsu.2020.02.034

7. Andersen KG, Rambaut A, Lipkin WI, Holmes EC, Garry RF. The proximal origin of SARS-CoV-2. Nat Med. 2020;26(4):450-452. doi:10.1038/s41591-020-0820-9

8. He F, Deng Y, Li W. Coronavirus disease 2019: what we know? J Med Virol. 2020;92(7):jmv.25766. doi:10.1002/jmv.25766

9. Verity R, Okell LC, Dorigatti I, et al. Estimates of the severity of coronavirus disease 2019: a model-based analysis. Lancet Infect Dis. 2020;20(6):669-677. doi:10.1016/S1473-3099(20)30243-7

10. Imai N, Cori A, Dorigatti I, et al. Report 3: transmissibility of 2019-nCoV. Imp Coll London. 2020. Available from: https://www. imperial.ac.uk/media/imperial-college/medicine/sph/ide/gidafellowships/Imperial-College-COVID19-transmissibility-25-01-2020. pdf.

11. Wu GZ, Wang JW, Xu JQ. Voice from China: nomenclature of the novel coronavirus and related diseases. Chin Med J (Engl). 2020;133 (9):1012-1014. doi:10.1097/CM9.0000000000000787

12. Gorbalenya AE, Baker SC, Baric RS, et al. The species severe acute respiratory syndrome-related coronavirus: classifying 2019-nCoV and naming it SARS-CoV-2. Nat Microbiol. 2020. doi:10.1038/s41564020-0695-Z

13. Wu A, Peng Y, Huang B, et al. Genome composition and divergence of the novel coronavirus (2019-nCoV) originating in China. Cell Host Microbe. 2020;27(3):325-328. doi:10.1016/j.chom.2020.02.001

14. Siu YL, Teoh KT, Lo J, et al. The M, E, and N structural proteins of the severe acute respiratory syndrome coronavirus are required for efficient assembly, trafficking, and release of virus-like particles. J Virol. 2008;82(22):11318-11330. doi:10.1128/jvi.01052-08

15. Kim D, Lee JY, Yang JS, Kim JW, Kim VN, Chang H. The architecture of SARS-CoV-2 transcriptome. Cell. 2020. doi:10.1016/j. cell.2020.04.011
16. Yuan M, Wu NC, Zhu X, et al. A highly conserved cryptic epitope in the receptor binding domains of SARS-CoV-2 and SARS-CoV. Science. 2020;368(6491):630-633. doi:10.1126/science.abb7269

17. Wang Q, Zhang Y, Wu L, et al. Structural and functional basis of SARS-CoV-2 entry by using human ACE2. Cell. 2020. doi:10.1016/ J.CELL.2020.03.045

18. Walls AC, Tortorici MA, Bosch BJ, et al. Cryo-electron microscopy structure of a coronavirus spike glycoprotein trimer. Nature. 2016;531(7592):114-117. doi:10.1038/nature16988

19. Ortega JT, Serrano ML, Pujol FH, Rangel HR. Role of changes in SARS-CoV-2 spike protein in the interaction with the human ACE2 receptor: an in silico analysis. EXCLI J. 2020. doi:10.17179/ excli2020-1167

20. Rambaut A, Holmes EC, O'Toole Á, et al. A dynamic nomenclature proposal for SARS-CoV-2 lineages to assist genomic epidemiology. Nat Microbiol. 2020;5(11):1403-1407. doi:10.1038/s41564-0200770-5

21. Rambaut A, Loman N, Pybus O, Barclay W. Preliminary genomic characterisation of an emergent SARS-CoV-2 lineage in the UK defined by a novel set of spike mutations. Virological. 2020. Available from: https://virological.org/t/preliminary-genomiccharacterisation-of-an-emergent-sars-cov-2-lineage-in-the-uk-defined -by-a-novel-set-of-spike-mutations $/ 563$.

22. Faulkner N, Ng K, Wu M, et al. Reduced antibody cross-reactivity following infection with B.1.1.7 than with parental SARS-CoV-2 strains. bioRxiv. 2021

23. Naveca F, Nascimento V, Souza V, et al. Phylogenetic relationship of SARS-CoV-2 sequences from Amazonas with emerging Brazilian variants harboring mutations $\mathrm{E} 484 \mathrm{~K}$ and $\mathrm{N} 501 \mathrm{Y}$ in the spike protein. virological.org. Available from: https://virological.org/t/phy logenetic-relationship-of-sars-cov-2-sequences-from-amazonas-withemerging-brazilian-variants-harboring-mutations-e484k-and-n501yin-the-spike-protein/585. Accessed May 12, 2021.

24. Millet JK, Whittaker GR. Host cell proteases: critical determinants of coronavirus tropism and pathogenesis. Virus Res. 2015;202:120-134. doi:10.1016/j.virusres.2014.11.021

25. Chen J. Pathogenicity and transmissibility of 2019-nCoV-a quick overview and comparison with other emerging viruses. Microbes Infect. 2020;22(2):69-71. doi:10.1016/j.micinf.2020.01.004

26. Weiss SR, Navas-Martin S. Coronavirus pathogenesis and the emerging pathogen severe acute respiratory syndrome coronavirus. Microbiol Mol Biol Rev. 2005;69(4):635-664. doi:10.1128/ mmbr.69.4.635-664.2005

27. V'kovski P, Kratzel A, Steiner S, Stalder H, Thiel V. Coronavirus biology and replication: implications for SARS-CoV-2. Nat Rev Microbiol. 2020;19(3):155-170. doi:10.1038/s41579-020-00468-6

28. Lee S, Channappanavar R, Kanneganti T-D. Coronaviruses: innate immunity, inflammasome activation, inflammatory cell death, and cytokines. Trends Immunol. 2020;41(12):1083-1099. doi:10.1016/j. it. 2020.10 .005

29. Stech O, Veits J, Weber S, et al. Acquisition of a polybasic hemagglutinin cleavage site by a low-pathogenic avian influenza virus is not sufficient for immediate transformation into a highly pathogenic strain. J Virol. 2009;83(11):5864-5868. doi:10.1128/ jvi.02649-08

30. Wang N, Shang J, Jiang S, Du L. Subunit vaccines against emerging pathogenic human coronaviruses. Front Microbiol. 2020;11:298. doi:10.3389/fmicb.2020.00298

31. Nakagawa K, Lokugamage KG, Makino S. Viral and cellular mRNA translation in coronavirus-infected cells. Adv Virus Res. 2016. doi:10.1016/bs.aivir.2016.08.001

32. Sola I, Almazán F, Zúñiga S, Enjuanes L. Continuous and discontinuous RNA synthesis in coronaviruses. Annu Rev Virol. 2015;2 (1):265-288. doi:10.1146/annurev-virology-100114-055218 
33. Viehweger A, Krautwurst S, Lamkiewicz K, et al. Direct RNA nanopore sequencing of full-length coronavirus genomes provides novel insights into structural variants and enables modification analysis. Genome Res. 2019;29(9):1545-1554. doi:10.1101/ gr. 247064.118

34. Wijegoonawardane PKM, Sittidilokratna N, Petchampai N, Cowley JA, Gudkovs N, Walker PJ. Homologous genetic recombination in the yellow head complex of nidoviruses infecting Penaeus monodon shrimp. Virology. 2009;390(1):79-88. doi:10.1016/j. virol.2009.04.015

35. Forni D, Cagliani R, Clerici M, Sironi M. Molecular evolution of human coronavirus genomes. Trends Microbiol. 2017;25(1):35-48. doi:10.1016/j.tim.2016.09.001

36. Gao Y, Yan L, Huang Y, et al. Structure of the RNA-dependent RNA polymerase from COVID-19 virus. Science. 2020;368 (6492):779-782. doi:10.1126/science.abb7498

37. Kirchdoerfer RN, Ward AB. Structure of the SARS-CoV nsp12 polymerase bound to nsp7 and nsp8 co-factors. Nat Commun. 2019;10(1):1-9. doi:10.1038/s41467-019-10280-3

38. Becares M, Pascual-Iglesias A, Nogales A, Sola I, Enjuanes L, Zuñiga S. Mutagenesis of coronavirus nsp14 reveals its potential role in modulation of the innate immune response. $J$ Virol. 2016;90 (11):5399-5414. doi:10.1128/JVI.03259-15

39. Eckerle LD, Becker MM, Halpin RA, et al. Infidelity of SARS-CoV Nsp14-exonuclease mutant virus replication is revealed by complete genome sequencing. PLoS Pathog. 2010;6(5):e1000896. doi:10.1371/ journal.ppat.1000896

40. Eckerle LD, Lu X, Sperry SM, Choi L, Denison MR. High fidelity of murine hepatitis virus replication is decreased in nsp14 exoribonuclease mutants. J Virol. 2007;81(22):12135-12144. doi:10.1128/ jvi.01296-07

41. Ferron F, Subissi L, De Morais ATS, et al. Structural and molecular basis of mismatch correction and ribavirin excision from coronavirus RNA. Proc Natl Acad Sci U S A. 2017;115(2):E162-E171. doi:10.1073/pnas.1718806115

42. Liu C, Zhou Q, Li Y, et al. Research and development on therapeutic agents and vaccines for COVID-19 and related human coronavirus diseases. ACS Cent Sci. 2020;6(3):315-331. doi:10.1021/ acscentsci.0c00272

43. Den Boon JA, Ahlquist P. Organelle-like membrane compartmentalization of positive-strand RNA virus replication factories. Annu Rev Microbiol. 2010;64(1):241-256. doi:10.1146/annurev.micro.11240. 134012

44. Tseng YT, Wang SM, Huang KJ, Lee AI-R, Chiang C-C, Wang C-T. Self-assembly of severe acute respiratory syndrome coronavirus membrane protein. J Biol Chem. 2010;285(17):12862-12872. doi:10.1074/jbc.M109.030270

45. Angelini MM, Akhlaghpour M, Neuman BW, Buchmeier MJ, Moscona A. Severe acute respiratory syndrome coronavirus nonstructural proteins 3, 4, and 6 induce double-membrane vesicles. MBio. 2013;4(4). doi:10.1128/mBio.00524-13

46. Hagemeijer MC, Monastyrska I, Griffith J, et al. Membrane rearrangements mediated by coronavirus nonstructural proteins 3 and 4 . Virology. 2014;458-459(1):125-135. doi:10.1016/j.virol.2014.04.027

47. Vabret N, Britton GJ, Gruber C, et al. Immunology of COVID-19: current state of the science. Immunity. 2020. doi:10.1016/j. immuni.2020.05.002

48. Channappanavar R, Fehr AR, Vijay R, et al. Dysregulated type $\mathrm{i}$ interferon and inflammatory monocyte-macrophage responses cause lethal pneumonia in SARS-CoV-infected mice. Cell Host Microbe. 2016;19(2):181-193. doi:10.1016/j.chom.2016.01.007

49. Kwon B, Ansari IH, Pattnaik AK, Osorio FA. Identification of virulence determinants of porcine reproductive and respiratory syndrome virus through construction of chimeric clones. Virology. 2008;380 (2):371-378. doi:10.1016/j.virol.2008.07.030
50. Yang Z, Zhang X, Wang F, Wang P, Kuang E, Li X. Suppression of MDA5-mediated antiviral immune responses by NSP8 of SARS-CoV-2. bioRxiv. 2020.

51. Wurm T, Chen H, Hodgson T, Britton P, Brooks G, Hiscox JA. Localization to the nucleolus is a common feature of coronavirus nucleoproteins, and the protein may disrupt host cell division. $J \quad$ Virol. 2001;75(19):9345-9356. doi:10.1128/jvi.75.19.93459356.2001

52. Lu X, Pan J, Tao J, Guo D. SARS-CoV nucleocapsid protein antagonizes IFN- $\beta$ response by targeting initial step of IFN- $\beta$ induction pathway, and its C-terminal region is critical for the antagonism. Virus Genes. 2011;42(1):37-45. doi:10.1007/s11262-010-0544-X

53. Gharbharan A, Jordans CCE, Geurtsvankessel C, et al. Convalescent plasma for COVID-19. A randomized clinical trial. medRxiv. 2020. doi:10.1101/2020.07.01.20139857

54. Wu F, Wang A, Liu M, et al. Neutralizing antibody responses to SARS-CoV-2 in a COVID-19 recovered patient cohort and their implications. medRxiv. 2020. doi:10.1101/2020.03.30.20047365

55. Lumley SF, O'Donnell D, Stoesser NE, et al. Antibody status and incidence of SARS-CoV-2 infection in health care workers. $N \mathrm{Engl}$ $J$ Med. 2021;384(6):533-540. doi:10.1056/nejmoa2034545

56. Hall VJ, Foulkes S, Charlett A, et al. Do antibody positive healthcare workers have lower SARS-CoV-2 infection rates than antibody negative healthcare workers? Large multi-centre prospective cohort study (the SIREN Study), England: June to November 2020. SSRN Electron J. 2021. doi:10.2139/ssrn.3768524

57. Garcia-Beltran WF, Lam EC, Astudillo MG, et al. COVID-19neutralizing antibodies predict disease severity and survival. Cell. 2021;184(2):476-488.e11. doi:10.1016/j.cell.2020.12.015

58. Tay MZ, Poh CM, Rénia L, MacAry PA, Ng LFP. The trinity of COVID-19: immunity, inflammation and intervention. Nat Rev Immunol. 2020;20(6):363-374. doi:10.1038/s41577-020-0311-8

59. Synowiec A, Szczepański A, Barreto-Duran E, Lie LK, Pyrc K. Severe acute respiratory syndrome coronavirus 2 (SAR S-CoV-2): a systemic infection. Clin Microbiol Rev. 2021;34(2):e00133-20. doi:10.1128/CMR.00133-20

60. Larson AS, Savastano L, Kadirvel R, Kallmes DF, Hassan AE, Brinjikji W. Coronavirus disease 2019 and the cerebrovascular-cardiovascular systems: what do we know so far? $J$ Am Heart Assoc. 2020;9(13). doi:10.1161/JAHA.120.016793

61. Marik PE, Kory P, Varon J, Iglesias J, Meduri GU. MATH+ protocol for the treatment of SARS-CoV-2 infection: the scientific rationale. Expert Rev Anti Infect Ther. 2021;19(2):129-135. doi:10.1080/ 14787210.2020.1808462

62. Kashour Z, Riaz M, Garbati MA, et al. Efficacy of chloroquine or hydroxychloroquine in COVID-19 patients: a systematic review and meta-analysis. $J$ Antimicrob Chemother. 2021;76(1):30-42. doi:10.1093/jac/dkaa403

63. Gasmi A, Peana M, Noor S, et al. Chloroquine and hydroxychloroquine in the treatment of COVID-19: the never-ending story. Appl Microbiol Biotechnol. 2021;105(4):1333-1343. doi:10.1007/s00253021-11094-4

64. Wang Y, Zhang D, Du G, et al. Remdesivir in adults with severe COVID-19: a randomised, double-blind, placebo-controlled, multicentre trial. Lancet. 2020;395(10236):1569-1578. doi:10.1016/ S0140-6736(20)31022-9

65. Wise J. Covid-19: convalescent plasma may cut deaths in patients not on ventilation, study indicates. BMJ. 2021. doi:10.1136/bmj.n130

66. Li -D-D, Li Q-H. SARS-CoV-2: vaccines in the pandemic era. Mil Med Res. 2021;8(1):1. doi:10.1186/s40779-020-00296-y

67. Liu Z, Zheng H, Yuan R, et al. Identification of a common deletion in the spike protein of SARS-CoV-2. bioRxiv. 2020. doi:10.1101/ 2020.03.31.015941

68. Mousavizadeh L, Ghasemi S. Genotype and phenotype of COVID-19: their roles in pathogenesis. J Microbiol Immunol Infect. 2020;54(2):159-163. doi:10.1016/j.jmii.2020.03.022 
69. Li W, Kuhn JH, Moore MJ, et al. Receptor and viral determinants of SARS-coronavirus adaptation to human ACE2. EMBO J. 2005;24 (8):1634-1643. doi:10.1038/sj.emboj.7600640

70. Wang Q, Wong G, Lu G, Yan J, Gao GF. MERS-CoV spike protein: targets for vaccines and therapeutics. Antiviral Res. 2016;133:165-177. doi:10.1016/j.antiviral.2016.07.015

71. Volz E, Mishra S, Chand M, et al. Transmission of SARS-CoV-2 Lineage B.1.1.7 in England: insights from linking epidemiological and genetic data. medRxiv. 2021.
72. Sabino EC, Buss LF, Carvalho MPS, et al. Resurgence of COVID-19 in Manaus, Brazil, despite high seroprevalence. Lancet. 2021;397 (10273):452-455. doi:10.1016/S0140-6736(21)00183-5

73. WHO. Weekly epidemiological update on COVID-19 - 20 April 2021. Available from: https://www.who.int/publications $/ \mathrm{m} / \mathrm{item} /$ weekly-epidemiological-update-on-covid-19-20-april-2021. Accessed 20 April 2021.

\section{Publish your work in this journal}

Infection and Drug Resistance is an international, peer-reviewed openaccess journal that focuses on the optimal treatment of infection (bacterial, fungal and viral) and the development and institution of preventive strategies to minimize the development and spread of resistance. The journal is specifically concerned with the epidemiology of antibiotic resistance and the mechanisms of resistance development and diffusion in both hospitals and the community. The manuscript management system is completely online and includes a very quick and fair peerreview system, which is all easy to use. Visit http://www.dovepress.com/ testimonials.php to read real quotes from published authors. 